\title{
As músicas da Era Vargas e o registro da Memória Social sobre as eleições presidenciais
}

\author{
The songs of the President Vargas's government and the Social Memory Registry on \\ presidential elections
}

Cleonice Della Pasqua Bacharel em Biblioteconomia pela Universidade Federal do Rio Grande do Sul - UFRGS.

E-mail: nicedupper@hotmail.com

Luis Fernando Herbert Massoni Doutorando em Comunicação e Informação pelo Programa de Pós-graduação em Comunicação e Informação da Universidade Federal do Rio Grande do Sul - UFRGS.

E-mail: luisfernandomassoni@gmail.com

$\begin{array}{r}\text { Ketlen Stueber } \\ \text { Doutoranda em Educação em Ciências Química da Vida e Saúde da Universidade Federal do Rio Grande do Sul } \\ - \text { UFRGS. } \\ \text { E-mail: ketistueber@hotmail.com }\end{array}$

\section{Resumo}

Estuda as músicas compostas durante as eleições presidenciais da Era Vargas, no período entre 1930 e 1954 . Lista quatro músicas compostas no período proposto, com seus respectivos autores e interpretes. Utiliza as músicas como fonte de informação sobre a memória política da época. Analisa de forma empírica, as letras das canções e os fatos aos quais que se referem, com relação à história. Traça um paralelo entre os fatos, as composições e a memória social. Conclui que a música é uma importante fonte de informação para a formação da memória social, através de suas letras.

Palavras-chave: Era Vargas. Música brasileira. Fonte de informação. Memória social.

\begin{abstract}
It studies the musical compositions during the presidential elections of President Vargas's government between 1930 and 1954. It lists four songs composed during the period proposed with their respectives authors and interpreters. It uses the songs as a source of information about the political memory of the time. It analyzes in an empirical way, the lyrics of the songs and the facts to which they refer in relation to the story. It draws a parallel between the facts, the compositions and the social memory. It concludes that music is an important source of information for the formation of social memory, through its lyrics.
\end{abstract}

Keywords: Vargas's government. Brazilian music. Information source. Social memory. 


\section{Introdução}

A humanidade sempre recorreu aos registros para construir sua memória, um apanhado de conhecimentos, realizações e experiências que pudessem perpetuar a existência de cada ser, em algum momento, neste mundo. As bibliotecas têm por objetivo reunir, guardar, conservar e disponibilizar documentos escritos em seus vários suportes, sendo que a oralidade também se constitui uma fonte de informação valiosa para a investigação científica. Sócrates é um exemplo do papel desenvolvido pela oralidade, pois nunca escrevia seus pensamentos filosóficos, apenas disseminava suas ideias em praça pública. Entretanto, os registros orais do conhecimento, às vezes, não são bem concebidos pela academia, devido ao seu questionável valor fidedigno.

Para além dos registros já consagrados pelos cientistas e pesquisadores, ou por qualquer pessoa que deseja a informação, outros suportes também podem servir como fonte de dados, informação e conhecimento. Isso porque a memória social não é apenas registrada através do patrimônio bibliográfico, embora este seja mais conhecido e valorizado. Ao contrário, os suportes de memória e informação são fruto da fruição estética e artística, manifestando-se das mais variadas formas, de acordo com a capacidade e os talentos do sujeito que os produz. A música, por exemplo, é uma popular e importante forma de expressão e, por isso, sua análise permite a percepção sobre processos históricos e socioculturais.

Deste modo, questiona-se: de que modo as eleições realizadas durante a Era Vargas são representadas nas músicas brasileiras produzidas na época? O objetivo deste trabalho é retratar as manifestações políticas nas músicas referentes às eleições presidenciais durante a Era Vargas. Para tanto, selecionou-se quatro marchinhas de carnaval compostas durante o período estipulado. As letras das músicas, juntamente com seus compositores e intérpretes, foram reconhecidas dentro do período histórico e analisadas segundo os pressupostos da memória social.

Compreendemos as músicas como registros históricos, sendo que a observação das letras das composições permite desvendar relatos dos acontecimentos, passando a música a atuar como fonte para a construção da memória social de uma época. A memória social está relacionada ao conjunto de indivíduos de uma sociedade, configurando-se como um constructo coletivo formado por camadas de lembranças e esquecimentos. As músicas são expressões artísticas carregadas de sentidos transmitidas simbolicamente. 


\section{Música e Memória Social na História do Brasil}

A primeira história da música no Brasil foi escrita em 1908, por Guilherme de Melo (1867-1932), e foi intitulada A música no Brasil: desde os tempos coloniais até o primeiro decênio da República. Já em 1926, Renato Almeida escreve História da Música Brasileira. Sobre o canto popular, o autor afirma: "o canto popular, em sua rudeza e ingenuidade, é um motivo permanente de emoção, em que o homem primitivo traduz em face da natureza o anseio de seu espírito, alegre ou nostálgico, de êxtase ou de temor" (ALMEIDA, 1926, p. 21). Com relação à formação da música brasileira, o autor cita o canto dos índios, ao qual se refere como sendo "de rythmos seccos e bárbaros", com uma cadência monótona, severa, rude, como se fosse produzida para acalmar os deuses a quem temiam; as árias sentimentais e comovedoras trazidas pelos portugueses e, por fim, o som africano, trazido pelos navios negreiros que, segundo o autor, possuíam "uma larga sensibilidade, apurada num contínuo sofrimento", dando as notas mais vibrantes aos cantos populares. A esta mistura de sons é que se dá a origem da música brasileira.

As marchinhas de carnaval foram o gênero musical escolhido para a realização deste estudo, sendo que elas tiveram o seu auge nos anos 1930, 1940 e 1950. O sucesso obtido foi resultado de melodias simples e de forte apelo popular com letras irônicas, engraçadas e de caráter ambíguo. O compasso binário, raramente quaternário e com o primeiro tempo fortemente acentuado das marchinhas agradava ao povo, e o apogeu das marchinhas está ligado à sua popularização. Trazendo críticas aos temas urbanos, elas tratavam do cotidiano e, muitas vezes, tinham conotação política. O ambíguo era explorado com o intento de dar leveza a temas político, ideológico e partidário. A partir da década de 1930, as marchinhas tornaram-se mais populares pela divulgação feita através do rádio.

Aliada ao rádio, que na Era Vargas era o veículo midiático utilizado pelo governo federal, a música toma a forma uníssona e se espalha por todos os cantos do país, servindo como propaganda política do presidente. Sobre esse aspecto, Gondar (2016) alega que o exame das mídias explica o paradoxo entre a lembrança e o esquecimento, pois a memória não se transforma apenas através das alterações dos jogos sociais ou dos jogos de forças, mas também por meio das mudanças das mídias técnicas. Isso significa que as técnicas de registro são um componente fundamental nas formas de construção da memória social. 
Introduzido no Brasil no início do século $\mathrm{XX}$, o rádio popularizou-se como meio de comunicação e expandiu-se rapidamente por meio da publicidade, tornando-se hegemônico na época, possibilitando a comercialização da música e a difusão e o consumo por parte de todas as camadas sociais (OLIVEN, 1983). As eleições de 1930, por exemplo, já contavam com a presença efetiva do rádio:

\begin{abstract}
A Rádio Educadora Paulista tinha entre seus associados Júlio Prestes, candidato à presidência da República. Esquecendo seus princípios puramente educativos, a emissora fez efetiva campanha para o candidato paulista. Dentro da rádio não se falava no nome de Getúlio Vargas, candidato da Aliança Liberal, pois isso era proibido. (CALABRE, 2004, p. 16).
\end{abstract}

Além de peça fundamental para difundir a cultura brasileira, o rádio também foi espaço de disputa política, briga pelo poder, promoção de governantes e divulgação de ideologias (DINIZ, 2008). Foi assim no mundo todo, mas no Brasil o rádio teve papel fundamental no conflito deflagrado em São Paulo, em 1932, contra o presidente Getúlio Vargas. As rádios paulistas convocaram muitos soldados para a luta contra o governo central, na chamada revolução constitucionalista.

Sete anos depois, quando já estava consolidado no poder, Getúlio resolveu usar braço forte na programação das rádios, criando um programa obrigatório para todas as emissoras, a "Hora do Brasil", mais tarde "Voz do Brasil”". Em 1940, o Estado Novo incorporou a Rádio Nacional ao patrimônio da União. Com recursos injetados pelo governo, a emissora montou uma programação de altíssima qualidade, na qual desfilou um elenco de grandes nomes. A Rádio Nacional tornou-se uma das principais emissoras do mundo.

Compreendemos que a música é um importante suporte de informação e memória social. Napolitano (2002, p. 2) abrevia em um parágrafo o significado da música na história, quando afirma:

A música, sobretudo a chamada 'música popular', ocupa no Brasil um lugar privilegiado na história sociocultural, lugar de mediações, fusões, encontros de diversas etnias, classes e regiões que formam o nosso grande mosaico nacional. Além disso, a música tem sido, ao menos em boa parte do século XX, a tradutora dos nossos dilemas nacionais e veículo de nossas utopias sociais. Para completar, ela conseguiu, ao menos nos últimos quarenta anos, atingir um grau de reconhecimento cultural que encontra poucos paralelos no mundo ocidental.

A música também pode servir de fonte de informação na identificação da memória, retratando momentos históricos através de suas letras, que contam do cotidiano, dos fenômenos sociais, políticos, econômicos, nos momentos de alegria e de tristeza. A canção e a música popular podem ser compreendidas, conforme Moraes (2000), como uma rica fonte de 
compreensão das realidades da cultura popular, desvendando a história dos setores da sociedade pouco lembrados na historiografia.

Esse uso pode ser questionado pelo caráter extremamente subjetivo das composições, pois registram os acontecimentos através do olhar do compositor, tornando-se uma imagem do coletivo. Cabe lembrar, entretanto, que qualquer movimento de trabalho e pesquisa com memória social sempre estará imbuído de uma perspectiva ética e política, tendo em vista que "há sempre uma concepção de memória social implicada na escolha do que conservar e do que interrogar. Há nessa escolha uma aposta, um penhor, uma intencionalidade quanto ao porvir" (GONDAR, 2016, p. 25). Isso significa que, inevitavelmente, pesquisar memória social é sempre comprometer-se com uma perspectiva política sobre o fenômeno estudado, configurando as reflexões no campo da memória social como um posicionamento perante o objeto de pesquisa.

Escolher uma fonte de informação é selecionar um ponto de vista sobre o fenômeno em análise, o que significa "dar voz e vez" a determinados sujeitos e silenciar outros. Quando se opta por apenas considerar válido para estudo da memória o registro bibliográfico, por exemplo, relega-se ao esquecimento todas as manifestações memorialísticas expressas pela oralidade. Contudo, o trabalho com memória social comporta esse aspecto, tendo em vista que, conforme Gondar (2016), a memória implica o esquecimento, pois lembrar de alguns fatos significa esquecer de outros.

Para que uma memória se configure e se delimite, coloca-se, antes de mais nada, o problema da seleção ou da escolha: a cada vez que escolhemos transformar determinadas ideias, percepções ou acontecimentos em lembranças, relegamos muitos outros ao esquecimento. Isso faz da memória o resultado de uma relação complexa e paradoxal entre processos de lembrar e de esquecer, que deixam de ser vistos como polaridades opostas e passam a integrar um vínculo de coexistência paradoxal (GONDAR, 2016, p. 29).

Outro aspecto a ser considerado é o da relação entre a música e a construção identitária, pois as canções moldam e atualizam a identidade cultural. A música é um objeto de construção da identidade de uma nação, pois é parte da cultura popular. Hall (2006) se questiona de que modo é contada a narrativa da cultura nacional e, em resposta, ele afirma:

[...] há a narrativa da nação, tal como é contada e recontada nas histórias e nas literaturas nacionais, na mídia e na cultura popular. Essas fornecem uma série de estórias, imagens, panoramas, cenários, eventos históricos, símbolos e rituais nacionais que simbolizam ou representam as experiências partilhadas, as perdas, os triunfos e os desastres que dão sentido à nação (HALL, 2006, p. 52). 
A música, nesse contexto, poderia servir para tensionar as narrativas nacionais sobre a identidade cultural, pois expande o escopo de perspectivas sobre os processos históricos, muitas vezes contrapondo-se à história oficial. Além disso, enquanto expressão subjetiva e singular, a música é uma exacerbação do ponto de vista do sujeito que a compõe, configurando-se como um suporte de memoração entre diferentes sujeitos de um mesmo coletivo. Nesse sentido, é levantado por Morigi, Rocha e Semensatto (2012, p. 184) que:

Um indivíduo para lembrar seu passado tem que se remeter às lembranças dos outros. São pontos de referência que estão fixados pela sociedade. Portanto, a memória coletiva envolve sentimentos de pertença e identidade, já que a memória é sempre dependente das interações e dos grupos sociais. A memória coletiva é caracterizada por um intenso componente afetivo que surge da interação e das experiências entre os membros da comunidade.

O que está em jogo é a identidade do grupo social, que é atualizada pelos sujeitos quando têm contato com as músicas produzidas em um contexto que lhes é familiar. Por exemplo, a música regionalista é um elemento simbólico componente da cultura e das tradições dos grupos regionais, articulando-se à memória do grupo social e operando como legitimadora de concepções consagradas, ao mesmo tempo em que reorganiza e atualiza o imaginário coletivo (MORIGI; BONOTTO, 2004). No meio acadêmico, fontes de informação alternativas ainda carecem de aporte para que se tornem admissíveis para a fundamentação teórica de pesquisas. No entanto, alguns autores admitem que estas fontes de informação podem ser ricas e plenamente aceitáveis, como diz Ginzburg (1987, p. 21):

[...] o fato da fonte não ser 'objetiva' não significa que ela seja inutilizável. A
'revolução documental' permitiu a ampliação do conceito de documento e retirou sua
pesada pretensão objetiva positivista. Assim, música/canção popular não deve
injustamente ser nomeada como uma fonte excessivamente subjetiva e,
consequentemente, desprezada como documento. Mesmo uma documentação exígua,
dispersa e renitente (como a canção popular), pode, portanto, ser aproveitada.

Sendo a música uma manifestação cultural que abrange o grupo social como um todo, seu conteúdo pode carregar a história e as narrativas da movimentação popular em sua bagagem. Este passado contado através das sentenças musicais poderá elucidar as opiniões, confrontar teorias, reavivar lembranças e "preparar o terreno" para um futuro mais promissor. Portanto, as músicas, enquanto fontes de informação, fazem parte de uma estrutura cultural rica em produção simbólica. Enquanto objeto de estudo, as músicas contribuem para a compreensão do panorama político inserido em diferentes contextos temporais. 


\section{Aspectos metodológicos}

A partir das relações teóricas acima tecidas, propõe-se um estudo sobre as memórias das eleições realizadas durante a Era Vargas nas músicas compostas naquele período histórico. Para tanto, utiliza-se a abordagem qualitativa para compreender o fenômeno em análise, através de uma pesquisa documental, a partir das composições musicais em questão. O corpus da pesquisa constitui-se de quatro marchinhas de carnaval compostas durante o período, englobando os dois momentos em que Vargas presidiu o país (1930-1945 e 1951-1954). As músicas foram selecionadas considerando-se o tema político e o gênero musical dentro do período proposto. No Quadro 1 encontram-se listadas as marchinhas, obedecendo a uma ordem cronológica.

Quadro 1 - Marchinhas de Carnaval Selecionadas como Objeto de Pesquisa

\begin{tabular}{|c|c|c|c|}
\hline Música & Autoria & Intérprete & Ano \\
\hline Comendo Bola & Hekel Tavares e Luís Peixoto & Jaime Redondo & 1929 \\
\hline $\begin{array}{c}\text { Ge-Gê }(\text { Seu } \\
\text { Getúlio) }\end{array}$ & Lamartine Babo & $\begin{array}{c}\text { Henrique } \\
\text { Domingues }\end{array}$ & 1931 \\
\hline $\begin{array}{c}\text { A Menina } \\
\text { Presidência }\end{array}$ & $\begin{array}{c}\text { Antônio Nássara e Cristóvão de } \\
\text { Alencar }\end{array}$ & Silvio Caldas & 1936 \\
\hline $\begin{array}{c}\text { Bota o Retrato do } \\
\text { Velho }\end{array}$ & Haroldo Lobo e Marino Pinto & Francisco Alves & 1951 \\
\hline
\end{tabular}

Fonte: dos autores, 2018.

Muitas músicas foram compostas no período em análise, mas foram selecionadas as que possuem um cunho político em suas letras e que se referem às eleições presidenciais, especificamente. A música popular pode falar muito sobre a história de um lugar, sobre seu povo, seus costumes, aspectos geográficos, alimentação, religião, etc. Sobre o estudo da história através da música, Napolitano (2007, p. 154) alega:

\footnotetext{
Os trabalhos que tratam a música popular como fonte ou objeto têm crescido exponencialmente na área de história, desde os anos 1990. Do ponto de vista acadêmico, este novo tema é tributário das primeiras abordagens da área de letras, sociologia ou antropologia. Ou seja, os estudos sobre música popular têm uma natureza interdisciplinar desde a sua origem.
}

Os registros musicais precisam ser devidamente considerados, analisados, armazenados e disponibilizados para o acesso de todos.

Com relação à análise de dados, este trabalho utiliza a análise de conteúdo, método usado para descrever e interpretar o conteúdo de documentos e textos (MORAES, 1999). Conduzindo as descrições sistemáticas, qualitativas ou quantitativas, a análise de conteúdo 
busca reinterpretar as mensagens e atingir uma compreensão de seus significados num nível que vai além de uma leitura comum. Assim, busca-se evidenciar que fatos e momentos históricos são narrados a partir das composições estudadas.

\section{A Memória Social nas músicas das eleições da Era Vargas}

A análise se pautou em relacionar os conteúdos contidos nas letras compostas com o momento histórico em que se inserem. Retratam os acontecimentos em torno dos fenômenos políticos da época, identificando comportamentos e opiniões da sociedade através das palavras dos compositores. A seguir, são apresentadas as quatro músicas, em ordem cronológica.

A marchinha Comendo Bola foi lançada em dezembro de 1929, composta por Hekel Tavares e Luís Peixoto e interpretada por Jaime Redondo. Sua letra é a seguinte:

“Gaúcho, meu irmãozinho / Meu irmãozinho mineiro / Seu Julinho é que vai ser / Porque esse tá de Julinho / É um caboclo brasileiro / Brasileiro como quê / Tudo o mais é gauchada / Tudo o mais não vale nada / Meu irmãozinho gaúcho / Se tu amarra a cavalada / Vendo as coisa mal parada / Não aguenta com o repuxo / Getúlio, você tá comendo bola / Não te mete com seu Júlio / Não te mete com seu Júlio / Que seu Júlio tem escola / Atrás do liberalismo / Ninguém vá que esse cinismo / É potoca, é brincadeira / Eu conheço muito tolo / Que acabou levando bolo / E bateu na geladeira / Eles pensam, seu Julinho / Que esse povo é zé-povinho / Que isso é pau de galinheiro / Que sem nota e sem carinho / O Brasil anda sozinho / Porque Deus é brasileiro / Getúlio, você tá comendo bola."

Em plena campanha eleitoral, Júlio Prestes era o candidato preferido do presidente Washington Luiz. Composta durante o período de sucessão presidencial de 1930, a música exalta a figura do candidato, ironizando a candidatura oposicionista de Getúlio Vargas. Vargas era o candidato apoiado pelos gaúchos, mineiros e paraibanos que haviam formado a Aliança Liberal. A rixa que existia entre o eixo central do país e o Rio Grande do Sul está representada pelo compositor nesta música.

A música retrata a divisão dos candidatos e do povo, que está de um lado ou de outro. Prestes é referido como "um caboclo brasileiro", representando o candidato como brasileiro independente do seu estado de origem. Neste sentido, constrói-se uma figura voltada aos ideais 
nacionalistas de um país com o poder centrado na região sudeste (mais especificamente, pertencentes ao estado de São Paulo).

Getúlio Vargas, mesmo com o apoio de Minas Gerais e tendo como vice João Pessoa, representa atributos de um distante Brasil-sul. O candidato da oposição é representado como parte da "gauchada". O compositor reforça a ideia dizendo: "Tudo o mais não vale nada". Ao mostrar seu apoio ao candidato Júlio Prestes, Jaime Redondo descreve a gauchada como um povo fraco e desprovido de virtudes.

$\mathrm{Na}$ expressão "Se tu amarra a cavalada", o autor lembra que, quando Getúlio recebeu o poder através da Junta Militar, os soldados revolucionários gaúchos comemoraram a vitória amarrando seus cavalos no obelisco da Avenida Rio Branco, no centro do Rio de Janeiro.

As gírias utilizadas pela malandragem característica dos compositores da época estão presentes na letra. Na frase "Getúlio você está comendo bola", o compositor quer dizer que o candidato está equivocado ao tentar se eleger. Ele segue dizendo: "Não se mete com seu Júlio", na tentativa de desencorajar Getúlio Vargas. Seguindo, o autor tenta desacreditar o liberalismo apregoado pelo candidato da oposição que havia formado a Aliança Liberal com outros partidários dizendo que "É potoca, é brincadeira": potoca significa mentira.

O compositor tenta chamar a atenção dos ouvintes, provavelmente para atingi-los em seu orgulho, quando chama de "muito tolo" aqueles que apoiavam a candidatura de Vargas. Segue na frase seguinte, desta vez se referindo à outra parte da população que apoiava Prestes, afirmando que "Eles pensam, seu Julinho / Que esse povo é zé-povinho", na tentativa de manipular as opiniões. A música representa a imagem de um Brasil verdadeiro de Júlio Prestes contra um Brasil desqualificado de Getúlio Vargas. A composição pretende influenciar parte da população que escolheria Getúlio Vargas como presidente. Neste sentido, as campanhas eleitorais podem articular-se através da tentativa de menosprezar o que não diz respeito aos (seus) interesses de acordo com os propósitos de determinado candidato ou situação.

O compositor faz referência à brasilidade como uma forma de sensibilizar o eleitorado a votar em Júlio Prestes, argumentando que ele é um autêntico brasileiro - "É um caboclo brasileiro / Brasileiro como quê". Ao fazer isso, o compositor apela para a identidade do povo brasileiro, mexendo com o seu orgulho e a própria compreensão que possui sobre si mesmo. Esse uso político da identidade na memória é alertado por Gondar (2016), para a qual reduzir a memória à identidade significa pô-la a serviço da sua manutenção. Ou seja: a música faz um 
uso político da identidade visando a legitimação de uma instância de poder, no caso, a eleição de Júlio Prestes, candidato de Washington Luiz.

Ainda no impacto da ascensão de Vargas, em 1931, Lamartine Babo compôs Ge Gê, apelido carinhoso usado pelos partidários de Getúlio Vargas, interpretada por Henrique Foréis Domingues, o Almirante. Sua letra é:

"Só mesmo com revolução / Graças ao rádio e ao parabélum / Nós vamos ter transformação / Neste Brasil verde-amarelo / Ge-e-Gê-/t-u-tu/l-li-o-/ Getúlio / Certa menina do Encantado / Cujo papai foi senador / Ao ver o povo de encarnado / Sem se pintar mudou de cor / Ge-e-Gê-/t-u-tu/l-li-o-/ Getúlio".

A marchinha se refere à Revolução de 1930. A letra exalta o país, citando suas cores simbólicas, o verde e o amarelo, e também enaltece a figura do candidato à presidência, Getúlio Vargas. A música tem o formato de um jingle, que passa a ser repetido pelas vozes da população em todo o país. O “rádio' citado na letra era o maior veículo de informação da época seu alcance se tornava praticamente ilimitado. "Parabélum" era uma marca de revólver da época, muito utilizado pelos revolucionários - a letra incita a população para aderir à revolução. A menção à cor "encarnado" remete à cor dos lenços dos caudilhos gaúchos, apoiadores de Vargas. Os compositores frequentemente se utilizavam de metáforas para dizerem o que pretendiam simbolizar. "Encantado" era um bairro nobre da cidade do Rio de Janeiro, que na época era a capital do país.

Todos ansiavam por um novo país e o Brasil da revolução significava um país da modernidade, do desenvolvimento. É uma nova ideologia, a da revolução, disseminada através da música. Quando o autor cita a "Certa menina do encantado / Cujo pai foi senador", faz referência ao medo que as elites tinham da revolução. Nesse momento, faz-se um uso político da memória que reforça o seu papel de transformação. A esse respeito, Gondar (2016, p. 19) salienta que é necessário distinguir a memória concebida como produção do poder, mantenedora dos valores de um grupo social, da memória “[...] enquanto componente ativo dos processos de transformação social e de produção de um futuro". O trecho em questão evidencia esse uso social da memória enquanto possibilidade de transgressão aos padrões sociais vigentes e a possibilidade de um futuro diferente do presente.

Em 1936, Sílvio Caldas grava a marchinha A Menina Presidência, de Antônio Nássara e Cristóvão Alencar, interpretada por Sílvio Caldas. A letra é: 
"A menina presidência / Vai rifar seu coração / E já tem três pretendentes / Todos três chapéus na mão / E quem será? / O homem, quem será? / Será "seu Manduca”? / Ou será "seu Vavá"? / Entre estes dois, meu coração balança porque / Na hora agá quem vai ficar é "seu Gegê" / Agora todo mundo dá palpite / Mas eu sei que no fim ninguém se explica / É melhor deixar como está / "Pra" depois então se ver como é que fica".

Durante o chamado "governo provisório" getulista, fala-se na possibilidade de eleições para a escolha do sucessor de Getúlio na presidência, com dois fortes candidatos: o então governador de São Paulo, Armando Salles de Oliveira (o seu Manduca), este com a candidatura já lançada, e o ministro Osvaldo Aranha (o seu Vavá), que na verdade nem sequer chegou a se candidatar. As eleições não aconteceram, pois Getúlio implantou no país o Estado Novo, com maior centralização do poder, ficando na presidência até 1945, quando foi deposto.

Getúlio Vargas, na ocasião, referido como "seu Gegê”, desejava essa vitória como a uma mulher. O compositor menciona "três pretendentes", fazendo uma alusão aos possíveis candidatos da próxima eleição presidencial, que seria em 1938. "Será seu Manduca / Ou será seu Vavá": o questionamento exclui Vargas. Como quem se refere a pretendentes amorosos, diz que "Entre estes dois, meu coração balança porque". O autor se refere à "menina presidência" representando a vontade de Getúlio, que desejava o cargo de presidente como quem deseja a uma mulher. O autor, visionário, enfatiza que "Na hora agá quem vai ficar é seu Gegê", apelido dado a Getúlio Vargas por seus admiradores. Entende-se que a intenção de Vargas é a manutenção do poder e suas atitudes políticas o levam a conquista da Pátria até ser deposto, em 1945.

Todas as ações do candidato Vargas o levam para um único fim: ao de se manter no poder. Desta forma, o candidato poderia convencer as pessoas de que ele seria a melhor solução, mesmo que para isso fosse necessário utilizar-se de um golpe de Estado, o que de fato ocorreu. Outro aspecto observado é o fato de a música apresentar os dois concorrentes, mas escolher um terceiro - Seu Gegê. Essa escolha, obviamente, é fruto de um posicionamento político do seu autor. A esse respeito, Bosi (1994) adverte que, na memória política, os juízos de valor intervêm com maior insistência, pois o sujeito, enquanto testemunha histórica, não apenas narra de maneira neutra os fatos: ele deseja também julgar, marcando o lado que escolheu no contexto narrado.

Em 1951, Bota o Retrato do Velho foi composta por Haroldo Lobo e Marino Pinto, na interpretação de Francisco Alves, com a seguinte letra: 
"Bota o retrato do velho outra vez / Bota no mesmo lugar / O sorriso do velhinho Faz a gente trabalhar / Eu já botei o meu / E tu, não vai botar? / Já enfeitei o meu / E tu vais enfeitar? / O sorriso do velhinho Faz a gente trabalhar”.

Durante seu governo no Estado Novo, Getúlio Vargas determinou que as repartições públicas tivessem o retrato do Presidente da República pendurado na parede. Porém, quando Getúlio Vargas foi deposto em 1945, suas fotos foram, mais do que depressa, retiradas. Cinco anos mais tarde, os retratos voltaram quando Getúlio foi reeleito.

Além de inúmeros objetos de campanha que pregavam a volta de Getúlio, com o slogan "Ele voltará", a marchinha Retrato do Velho, na voz de Francisco Alves, foi sucesso absoluto no carnaval de 1951. A letra comenta a prática instituída pelo Estado Novo (e sustentada pelos governos posteriores), que recomendava a colocação de retratos do presidente nas paredes das repartições públicas. Vargas era um estrategista e contava com a disseminação de sua propaganda para conquistar o povo. Instituiu o feriado de $1^{\circ}$ de maio, dia dos trabalhadores, e reunia multidões em seus discursos. Na frase "O sorriso do velhinho / Faz a gente trabalhar", o autor reforça a ideia de que a simpatia do presidente cativava a população e incentivava o trabalho, base de sua ideologia. "Bota no mesmo lugar" indica a antiga prática exercida por todos.

Getúlio Vargas já estava no poder há muitos anos e, em 1951, ano em que a marchinha foi composta, o presidente estava com 68 anos. O compositor o chama de "Velho" em uma demonstração de afeto pela figura do presidente que poderia ser partilhada por todos. O retrato do Velho havia se tornado um símbolo nacional, em uma espécie de vigilância que exercia aos trabalhadores, mesmo que apenas através de um retrato na parede. Vargas obrigava a todos que mantivessem o retrato nas salas de aulas ou repartições públicas, independendo, para tal, as convicções políticas dos responsáveis pelos locais, o que representava seu poder.

Quando Vargas foi deposto, todos os retratos foram retirados das repartições públicas e das escolas, numa tentativa de promover o esquecimento das pessoas sobre aquele período em que estava no poder. Segundo Gondar (2016, p. 32):

Um grupo, uma sociedade, um país, também constroem uma imagem sobre si mesmos, e, portanto, uma identidade. Produzi-la e mantê-la não é tarefa fácil. Tratase de um esforço constante, exigindo que se "esqueça" - que se exclua, segregue ou recalque - tudo aquilo que se mostra em desacordo com a imagem que se tenta preservar. 
Passado o momento crítico, e tendo o candidato sido eleito para governar novamente, a ordem era para que os retratos fossem colocados de volta aos seus lugares. A música retrata o carinho por Getúlio Vargas, expresso na apreciação de sua imagem no retrato. Enquanto ato simbólico, a colocação e a retirada dos retratos configuram jogos de lembrança e esquecimento, próprios do trabalho com memória social. Nesse sentido, mais do que uma forma de demonstrar poder e influência, a presença dos retratos representava um ato memorialístico, pois mantinha constantemente presente a figura de Getúlio. Ele era, assim, lembrado através de sua imagem.

\section{Considerações finais}

A música brasileira, com sua riqueza de gêneros e sons, conta muito sobre nossa história, nossa cultura, a geografia do país, os sentimentos, as perdas, revoluções... para além de tudo isto, a música brasileira também pode ser uma fonte inestimável de informação para conhecermos a história, a sociedade, suas representações e a construção da memória social.

Partiu-se da reflexão a respeito da música e de sua contribuição para a história e para a memória social, para compreendê-la como uma fonte de informação que atualiza a construção de uma memória socialmente compartilhada. Verificou-se que, através das músicas escolhidas, e seguindo uma ordem cronológica, pode-se entender o panorama sócio histórico da época. Uma forte razão para que as músicas possam ser consideradas como fontes de informação, pesquisa e estudo.

É neste universo que a música se faz presente para a identificação dos momentos históricos e da ressignificação da memória social através de suas letras, que contam muito do cotidiano, dos fenômenos sociais, políticos, econômicos, dentre tantos outros. A utilização da música como uma linguagem alternativa para a construção da memória social é de extrema relevância, pois ativa as lembranças através do afeto, acrescenta novos conhecimentos, traz novos olhares sobre o passado e auxilia na construção do futuro. 


\section{Referências}

ALMEIDA, R. História da música brasileira. Rio de Janeiro: F. Briguiet \& Comp, 1926.

BABO, L. Ge-Gê (Seu Getúlio). Interprete: Henrique Foreis Domingues, o Almirante com o Bando Tangaras. 1931. Disponível em:

<http://memorialdademocracia.com.br/ajax_audio_extra_item/1346>. Acesso em: $12 \mathrm{abr}$. 2019.

BOSI, E. Memória e sociedade: lembranças de velhos. 3. ed. São Paulo: Companhia das Letras, 1994.

CALABRE, L. A era do rádio. 2. ed. Rio de Janeiro: Jorge Zahar, 2004.

DINIZ, A. Almanaque do carnaval: a história do carnaval, o que ouvir, o que ler, onde curtir. Rio de Janeiro: Jorge Zahar, 2008.

GINZBURG, C. O queijo e os vermes. São Paulo: Cia. das Letras, 1987.

GONDAR, J. Cinco proposições sobre memória social. Morpheus, Rio de Janeiro, v. 9, n. 15, p. 19-40, 2016.

HALL, S. As culturas nacionais como comunidades imaginárias. In: HALL, S. A identidade cultural na pós-modernidade. 11. ed. Rio de Janeiro: DP\&A, 2006. p. 47-57.

LOBO, H.; PINTO, M. Retrato do velho. Intérprete: Francisco Alves. 1951. Disponível em: <http://memorialdademocracia.com.br/ajax_audio_extra_item/1258>. Acesso em: $12 \mathrm{abr}$. 2019.

MORAES, J. G. V. História e música: canção popular e conhecimento histórico. Revista Brasileira de História, São Paulo, v. 20, n. 39, p. 203-221, 2000.

MORAES, R. Análise de conteúdo. Revista Educação, Porto Alegre, v. 22, n. 37, p. 7-32, 1999.

MORIGI, V. J.; BONOTTO, M. E. K. K. A narrativa musical, memória e fonte de informação afetiva. Em questão, Porto Alegre, v. 10, n. 1, p.1 43-161, jan./jun. 2004.

MORIGI, V. J.; ROCHA, C. P. V.; SEMENSATTO, S. Memória, representações sociais e cultura imaterial. Morpheus: Revista eletrônica em Ciências Humanas, [s.l.], v. 9, n. 14, p. 182-191, 2012.

NÁSSARA, A; ALENCAR, C. A menina presidência. Interprete: Silvio Caldas. 1937. Disponível em: <http://memorialdademocracia.com.br/ajax_audio_extra_item/1357>. Acesso em: 12 abr. 2019.

NAPOLITANO, M. História e música: história cultural da música popular. Belo Horizonte: Autêntica, 2002. 
NAPOLITANO, M. História e música popular: um mapa de leituras e questões. Revista de História, São Paulo, v. 157, p. 153-171, 2007.

OLIVEN, R. G. A elaboração de símbolos nacionais na cultura brasileira. Revista de Antropologia, São Paulo, v. 26, p. 107-118, dez. 1983.

TAVARES, H.; PEIXOTO, L. Comendo bola. Interprete: Jaime Redondo e grupo Regional. 1929. Disponível em: 〈http://memorialdademocracia.com.br/ajax_audio_extra_item/1336>. Acesso em: 12 abr. 2019.

Artigo submetido em: 06 ago. 2018

Artigo aceito em: 05 abr. 2019 